cambridge.org/cty

\section{Original Article}

Cite this article: Pierick AR, Pierick TA, and Reinking BE (2020) Comparison of growth and feeding method in infants with and without genetic abnormalities after neonatal cardiac surgery. Cardiology in the Young 30: 1826-1832. doi: $10.1017 /$ S1047951120002887

Received: 3 April 2020

Revised: 14 August 2020

Accepted: 21 August 2020

First published online: 25 September 2020

\section{Keywords:}

Critical congenital heart disease; growth; feeding method; genetic abnormality

\section{Author for Correspondence:}

A. Pierick, Emory University School of Medicine, Department of Pediatrics, 49 Jesse Hill Jr Dr SE, Atlanta, GA, USA 30303. Tel: +(319)541-8325.

E-mail: Alysonpierick8@gmail.com (c) The Author(s), 2020. Published by Cambridge University Press. This is an Open Access article, distributed under the terms of the Creative Commons Attribution licence (http:// creativecommons.org/licenses/by/4.0/), which permits unrestricted re-use, distribution, and reproduction in any medium, provided the original work is properly cited.

\title{
Comparison of growth and feeding method in infants with and without genetic abnormalities after neonatal cardiac surgery
}

\author{
Alyson R. Pierick ${ }^{1}$, Trudy A. Pierick $^{2}$ and Benjamin E. Reinking ${ }^{2}$
}

${ }^{1}$ Emory University School of Medicine, Department of Pediatrics, Atlanta, GA, USA and ${ }^{2}$ University of lowa Stead Family Children's Hospital, Department of Pediatrics, lowa City, IA, USA

\begin{abstract}
Introduction: Congenital heart disease (CHD) is multifactorial in origin, resulting from an interaction between environmental and genetic factors. Multifactorial growth delay is common in infants with CHD. The impact of a genetic abnormality and CHD on the growth of an infant is lacking in the literature. The aim of this study is to compare the growth and method of feeding following neonatal cardiac surgery in infants with normal versus abnormal genetic testing. Methods: A retrospective chart review of neonates who underwent a Risk Adjustment in Congenital Heart Surgery IV-VI procedure between 1 January, 2006 and 22 September, 2016 was performed at our institution. Weight, length, head circumference measurements, and feeding method were collected at birth, time of neonatal surgery, and monthly up to 6 months of age. Results: A total of 53 infants met inclusion criteria, of which 22 had abnormal genetic testing. Approximately $90 \%$ of infants were discharged following neonatal cardiac surgery with supplemental tube feeds. At each monthly follow-up visit, more infants were exclusively fed orally: $80 \%$ of infants with normal genetics at 5 months post-operative follow-up versus $60 \%$ of infants with abnormal genetic testing, although statistically insignificant. Growth was not different among the two groups. Conclusions: Infants with critical CHD with or without genetic abnormalities are at risk for growth delays and many need supplemental tube feeds post-operatively and throughout follow-up. Infants with genetic abnormalities are slower to achieve oral feeds and more likely to require tube feedings. It is important to have a systematic protocol for managing these high-risk infants.
\end{abstract}

\section{Introduction}

Congenital heart disease (CHD) is the most common congenital malformation, occurring in nearly $1 \%$ of newborns. ${ }^{1}$ While many infants with CHD have normal life expectancies and require minimal medical care, those with critical $\mathrm{CHD}$ (defined as a lesion requiring a Risk Adjustment in Congenital Heart Surgery (RACHS) IV-VI neonatal surgery) frequently require surgery in the neonatal period. ${ }^{2}$ Over the last few decades, advances in procedural techniques and post-operative care have improved survival. ${ }^{3}$ As a result, attention has shifted to decreasing morbidities and improving long-term quality of life.

Optimising nutrition and growth, specifically in the peri- and post-operative period, improves outcomes. ${ }^{4-9}$ Poor nutrition and growth in the pre-operative period are associated with poor neurodevelopmental outcomes, impaired wound healing, higher infection rates, and longer hospital length of stay. ${ }^{4,5,10}$ Growth delay is multifactorial and can be secondary to cardiac failure, non-cardiac anomalies, tachypnea, increased energy expenditures, inadequate caloric intake, gastroesophageal reflux, dysphagia, oral aversion, and vocal cord dysfunction.,11,12 Extracardiac malformations, often associated with genetic abnormalities, may also contribute to growth delay. ${ }^{13}$

Determining genetic abnormalities in infants with CHD is important when considering noncardiac morbidities. Neurodevelopmental disability, respiratory disease, renal disease, and growth delay are all common in patients with genetic defects. The growth of patients with trisomy 21 and Turner syndrome, for example, is monitored using syndrome specific growth charts. ${ }^{14}$ The presence of non-cardiac or genetic abnormalities in patients undergoing neonatal cardiac surgery is associated with increased mortality, longer intensive care unit stay, and prolonged hospital stay. ${ }^{15}$

The aim of this study was to determine the impact of genetic abnormalities on the growth and method of feeding from birth to 6 months of age in infants with critical CHD following neonatal cardiac surgery.

\section{Materials and methods}

Internal Institutional Review Board approval was obtained for a retrospective chart review of all patients who underwent a RACHS IV-VI procedure in the neonatal period at the University of Iowa Stead Family Children's Hospital between 1 January, 2006 and 22 September, 2016. 
Table 1. Demographic data

\begin{tabular}{|c|c|c|c|}
\hline & $\begin{array}{c}\text { Normal } \\
\text { genetics N } \\
(\%)\end{array}$ & $\begin{array}{c}\text { Abnormal } \\
\text { genetics N } \\
(\%)\end{array}$ & \\
\hline Total & $31(58.5)$ & $22(41.5)$ & \\
\hline Male & $23(74)^{\star}$ & $6(27.2)$ & $\begin{array}{l}Z=3.38 \\
\mathbf{p}<\mathbf{0 . 0 0 1}\end{array}$ \\
\hline Gestational age (days) & $271+/-11$ & $272+1-8$ & $p=0.59$ \\
\hline Prenatal diagnosis & 17 & 11 & $\begin{array}{l}Z=0.476 \\
p=0.634\end{array}$ \\
\hline \multicolumn{4}{|l|}{ Main cardiac diagnosis } \\
\hline $\begin{array}{l}\text { Hypoplastic Left Heart Syndrome } \\
\text { variant (14) }\end{array}$ & 10 & 4 & $p=0.252$ \\
\hline NON HLHS single ventricle (9) & 6 & 3 & $p=0.304$ \\
\hline Unbalanced AV Canal (2) & 1 & 1 & \\
\hline DORV variants (4) & 2 & 2 & \\
\hline Ebstein's anomaly (3) & 3 & 0 & \\
\hline Arch anomalies (15) & 4 & $11^{\star}$ & $\begin{array}{l}Z=2.954 \\
\mathbf{p}=\mathbf{0 . 0 0 3}\end{array}$ \\
\hline Coarctation (7) & 4 & 3 & \\
\hline Coarctation + VSD (7) & 0 & 7 & \\
\hline Interrupted aortic arch (1) & 0 & 1 & \\
\hline D-TGA variants (7) & 5 & 2 & $p=0.803$ \\
\hline D-TGA, VSD, coarctation (2) & 2 & 0 & \\
\hline D-TGA VSD (5) & 3 & 2 & \\
\hline TAPVR variant (6) & 4 & 2 & $p=0.66$ \\
\hline Truncus arteriosus & 1 & 0 & $p=0.395$ \\
\hline Critical aortic stenosis & 1 & 0 & $p=0.395$ \\
\hline
\end{tabular}

Abbreviations: D-TGA = dextro-transposition of the great arteries; DORV = double outlet right ventricle; HLHS = hypoplastic left heart syndrome; TAPVR = total anomalous pulmonary venous return; unbalanced $\mathrm{AV}$ canal $=$ unbalanced atrioventricular canal; VSD = ventricular septal defect.

${ }^{\star}=$ significant difference on Chi-square analysis.

All neonates without genetic testing, those who were lost to follow up and those who died before 6 months of age, were excluded from analysis.

Growth parameters including weight, length, and head circumference were extracted from the electronic medical record at birth, the time of surgery, and at monthly intervals until 6 months of age. The route of feeding (enteral tube, oral, or combination of oral and enteral tube) was collected at birth, at the time of hospital discharge, and monthly from the time of surgery for the first 5 months. The number of subjects receiving feedings by each method was determined at each time point. Individuals were separated into groups based on genetic testing results (normal or abnormal). Study data were collected and managed using REDCap electronic data tools hosted at the University of Iowa.

\section{Statistical analysis}

Demographic and clinical variables were compared among groups with normal and abnormal genetic testing using Pearson Chi-square test for the categorical variables. Linear regression models were used to assess the association between the growth end points (weight, length, and head circumference) and explanatory
Table 2. Genetic defects and associated cardiac diagnoses. Arch anomalies were defined as coarctation, hypoplastic aortic arch, or interrupted aortic arch. D-TGA variants included isolated D-TGA +/- ventricular septal defect and coarctation

\begin{tabular}{|c|c|}
\hline Cardiac diagnosis & Genetic defect \\
\hline \multirow{4}{*}{$\begin{array}{l}\text { Hypoplastic Left Heart } \\
\text { Syndrome }\end{array}$} & $94 \mathrm{~kb}$ deletion of $13 q 13.1$ \\
\hline & $1.4 \mathrm{Mb}$ deletion at $3 q 13.12 q 13.13$ \\
\hline & translocation at $5 p 14.1$ and $18 q 11.2$ \\
\hline & $505 \mathrm{~kb}$ duplication of $15 q 11.2$ \\
\hline \multirow[t]{3}{*}{ Non-HLHS single ventricle } & $914 \mathrm{~kb}$ duplication at $11 \mathrm{p} 14.1$ \\
\hline & $520 \mathrm{~kb}$ duplication of $15 q 11.2$ \\
\hline & $319 \mathrm{~kb}$ deletion at $15 \mathrm{q} 11.2$ \\
\hline \multirow[t]{11}{*}{ Arch anomalies } & $350 \mathrm{~kb}$ duplication at $15 q 22.33$ \\
\hline & $22 q 11.2$ deletion \\
\hline & $22 q 11.2$ deletion \\
\hline & $142 \mathrm{~kb}$ duplication of $1 \mathrm{q} 44$ \\
\hline & $45 \times 0$ \\
\hline & $47 X Y+21$ \\
\hline & $\begin{array}{l}171 \mathrm{~kb} \text { deletion of } 10 \mathrm{p} 15.2,268 \mathrm{~kb} \\
\text { duplication of } 21 \mathrm{q} 22.3\end{array}$ \\
\hline & $\begin{array}{l}917 \mathrm{~kb} \text { deletion of } 16 \mathrm{q} 24.1 ; 1.6 \mathrm{Mb} \\
\text { duplication of } 2 \mathrm{p} 12\end{array}$ \\
\hline & $308 \mathrm{~kb}$ deletion of $13 q 12.11$, Xo \\
\hline & $512 \mathrm{~kb}$ deletion of $15 q 11.2$ \\
\hline & $47 X Y+21$ \\
\hline D-TGA variants & $951 \mathrm{~kb}$ deletion at $20 \mathrm{p} 12.1$ \\
\hline \multirow[t]{2}{*}{ TAPVR } & $191 \mathrm{~kb}$ duplication at $6 \mathrm{q} 26$ \\
\hline & $\begin{array}{l}7.9 \mathrm{Mb} \text { deletion of } 18 \mathrm{p} 11.32 \mathrm{p} 11.23 \text { (18p } \\
\text { deletion syndrome) }\end{array}$ \\
\hline
\end{tabular}

Abbreviations: $\mathrm{HLHS}=$ hypoplastic left heart syndrome; TAVPR = total anomalous pulmonary venous return; $\mathrm{D}-\mathrm{TGA}=\mathrm{D}$-transposition of the great vessels.

variables (single ventricle versus two ventricle $\mathrm{CHD}$, gender, gestational age at birth, and genetic testing result). Multivariable logistic regression models were performed to identify independent variables associated with feeding method outcomes. Independent variables for regression models were defined as single ventricle versus two ventricle $\mathrm{CHD}$, gender, gestational age at birth, and genetic testing result. Significance was assessed at the 0.05 level.

\section{Results}

\section{Demographics}

During the study period, 97 patients underwent RACHS IV-VI procedures. Of those neonates, 7 were excluded because they were lost to follow up and 18 were excluded due to death before 6 months of age. Of the remaining 72 newborns, 53 had genetic testing performed and were included for further analysis. In total, 29 infants $(54.7 \%)$ were male. Genetic defects were identified in 22 infants $(41.5 \%)$. There were significantly more males $(\mathrm{p}<0.001)$ in the group with normal genetic testing. Gestational age and rate of prenatal diagnosis were similar in both groups. Demographic data including cardiac diagnosis can be found in Table 1. Information on the identified genetic defects and the associated cardiac lesions can be found in Table 2 . 


\section{Anthropomorphic measurements}

Weight, length, and head circumference measurements were collected for each infant at birth, time of surgery, and each month following surgery until 6 months of age. Although infants with genetic defects weighed less than those with normal genetic testing at every time point, the difference was not statistically significant. Similarly, length and head circumference measurements were less in those with abnormal genetic testing than in those with normal genetic testing at every time point. Those with genetic defects were noted to have significantly smaller head circumference at 5 months of age $(p<0.01)$ and shorter lengths at 3 months of age $(p=0.02)$ and 6 months of age $(p<0.01)$. Length and head circumference measurements were not significantly different between the two groups at any other time point. Growth data is summarised in the Figure 1. Data was not available for each subject at all time points. The number of subjects included at each time point can be found in the figures. Significant differences between the normal and abnormal genetic groups are designated with a star.

Linear regression models assessing anthropometric measurements with potential confounders showed that increasing gestational age was significantly associated with increasing weight, length, and head circumference at each time point. Although statistically insignificant, abnormal genetic test results, female gender, and single ventricle physiology were negatively associated. Results of the linear regression can be found in Table 3 .

\section{Method of feeding}

Feeding method from the post-operative period to 6 months of age is summarised in Table 4. In both groups, most infants received feeds via an enteral tube in the immediate post-operative period. At each subsequent follow up visit, the percentage of infants exclusively orally fed increased. Those with normal genetic testing transitioned to all oral feeds more quickly than those with genetic defects, with significantly more infants taking all oral feeds at 3 months and 4 months of age. By 5 months of age, those with abnormal genetic testing taking feeds orally increased and there was no significant difference between the two groups. Multinomial logistic regression models found that no variable significantly impacted the method of feeding between the immediate post-operative period and at 5 months post operation. Results of the regression model can be found in Table 5 .

\section{Discussion}

In this retrospective chart review, we evaluated newborns with critical CHD who underwent a neonatal cardiac surgery and compared growth and method of feeding of those with normal and abnormal genetic testing. We found that at our centre, there was no difference in growth parameters from birth to 6 months of age in these infants regardless of genetic testing. Infants with genetic abnormalities were slower to reach full oral feeds even at 5 months after surgery.

The rate of genetic abnormalities in our study population was similar to published values. ${ }^{16}$ There was, however, an important difference in the demographics of the two groups. The percentage of females was significantly greater in the abnormal genetic testing group. While the reason for the female predominance in this study could be related to gender differences in specific congenital heart defects, ${ }^{17-19}$ it could also be related to the small sample size of our single center study.
Growth following neonatal cardiac surgeries, specifically following the Norwood procedure, has been well studied. ${ }^{4,5,8,20-22,20,23}$ With the recognition that infants post Norwood procedure have increased caloric needs, most institutions have instituted specific home-monitoring programs focussing on weight gain and increased surveillance during the inter-stage period. Poor weight gain has been associated with more post-operative complications, longer hospital stays, and worse neurodevelopmental outcomes. ${ }^{4,10,21,24}$ Length has also been studied, with these infants on average being shorter at birth and not recovering to a normal height even with proper nutrition, ${ }^{4,21,25}$ indicating there may be some other component contributing to growth in height. Most of these studies have excluded infants with recognised chromosomal abnormalities.

While the infants with abnormal genetic testing were smaller at almost every time point than those with normal genetic testing, few statistically significant differences were found among the groups in this study. We hypothesise that this is due to a programmatic emphasis on post-operative growth and nutrition in all infants who undergo complex neonatal cardiac surgeries. During the study period, our institution joined the National Paediatric Cardiology Quality Improvement Collaborative (NPC-QIC) in 2012. Membership in this collaborative changed discharge and feeding protocols during the study period.

Prior to joining the collaborative, we discharged all neonatal cardiac patients in the same manner, without respect to diagnosis or genetic defects. Parents received extensive teaching from nursing staff regarding their infant's cares, including mixing formula or breast milk correctly, inserting nasogastric tubes, and giving medications and feedings per nasogastric tube. Once competence was demonstrated, parents completed an apartment experience for 24-48 hours in which they provided all cares for the infant using home equipment. The patient was then discharged with a daily home worksheet documenting feedings, output, medications, vitals from home nursing visits, and oxygen saturations if the patient was a single ventricle. Patients were followed by the primary cardiologist at routine intervals with outpatient feeding management by the cardiology nurse practitioner and dietitian, adjusting to maintain an average weight gain of $15-20 \mathrm{gm} /$ day.

After joining the collaborative, many of these practices regarding feeding, discharge preparation, and outpatient management remained the same. An official home-monitoring program for inter-stage care of single ventricle and shunt dependent infants was developed in 2012. Families were now given a baby scale to document daily weights and learned how to calculate weight changes with a goal of 60 gm over a 4 -day period. Outpatient management of this group was restructured to a team of two cardiologists, a cardiology nurse practitioner, and a dietician. Interval growth goals remained the same. Those infants followed outside of the inter-stage clinic had growth managed by the primary cardiologist, cardiology nurse practitioner, and dietitian, with less frequent weight collection (at clinical visits) but similar growth goals to the single ventricle patients. The consistency of feeding management by these same care providers, regardless of cardiac or genetic diagnosis, validates our findings over this 10-year period, even with programmatic changes in care.

At the time of discharge, $\sim 90 \%$ of infants in this study required nutrition via an enteral tube, regardless of genetic testing results. Those with normal genetic testing, however, progressed more quickly in their oral feeding skills, with a significantly greater number receiving at least a portion of their nutrition orally at 3 and 4 months of age. This difference could be due to the increased risk for neurodevelopmental delay, abnormal muscle tone, and 
(a)

Weight from Birth to 6 Months Post-operation

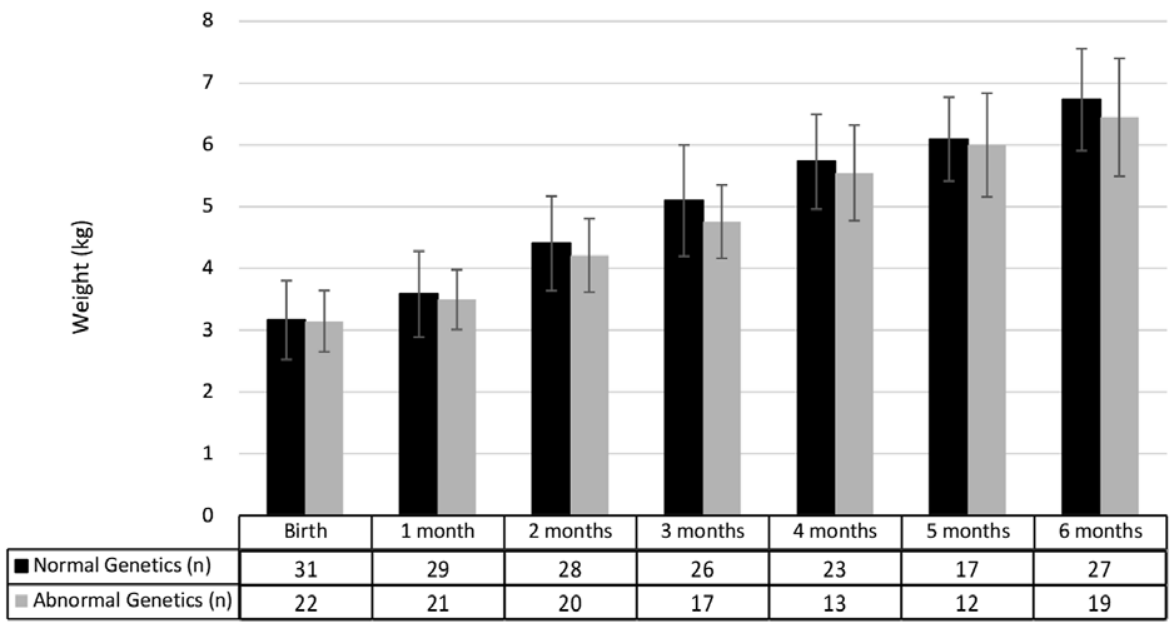

Weight

(b)

Length from Birth to 6 Months Post-operation

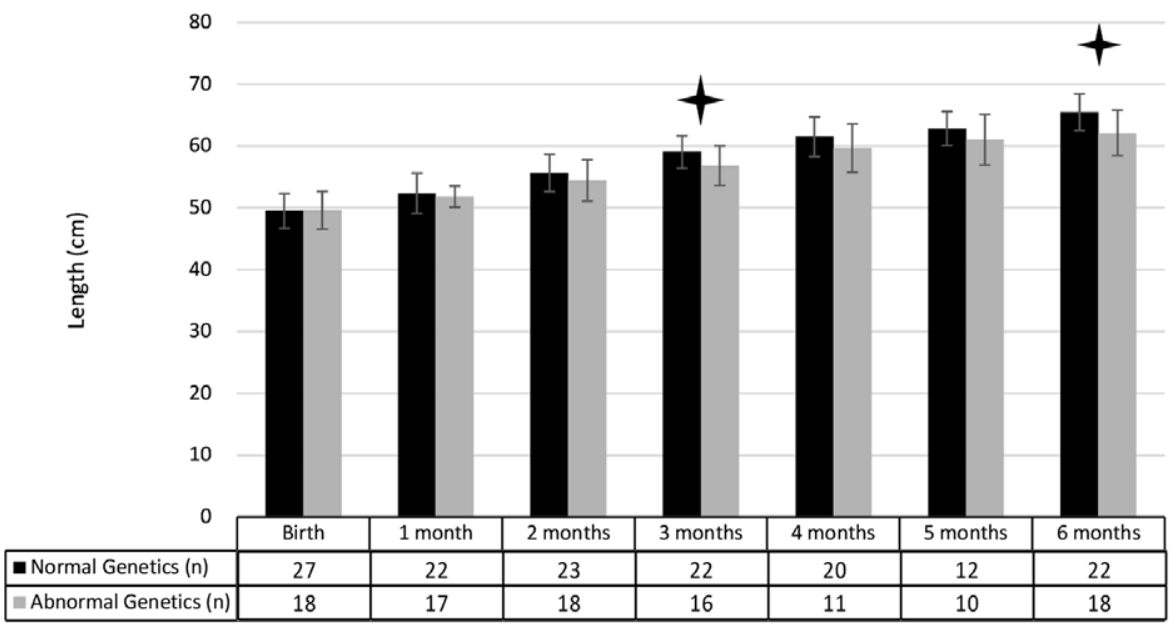

Length

(c)

Head Circumference from Birth to 6 Months Post-operation

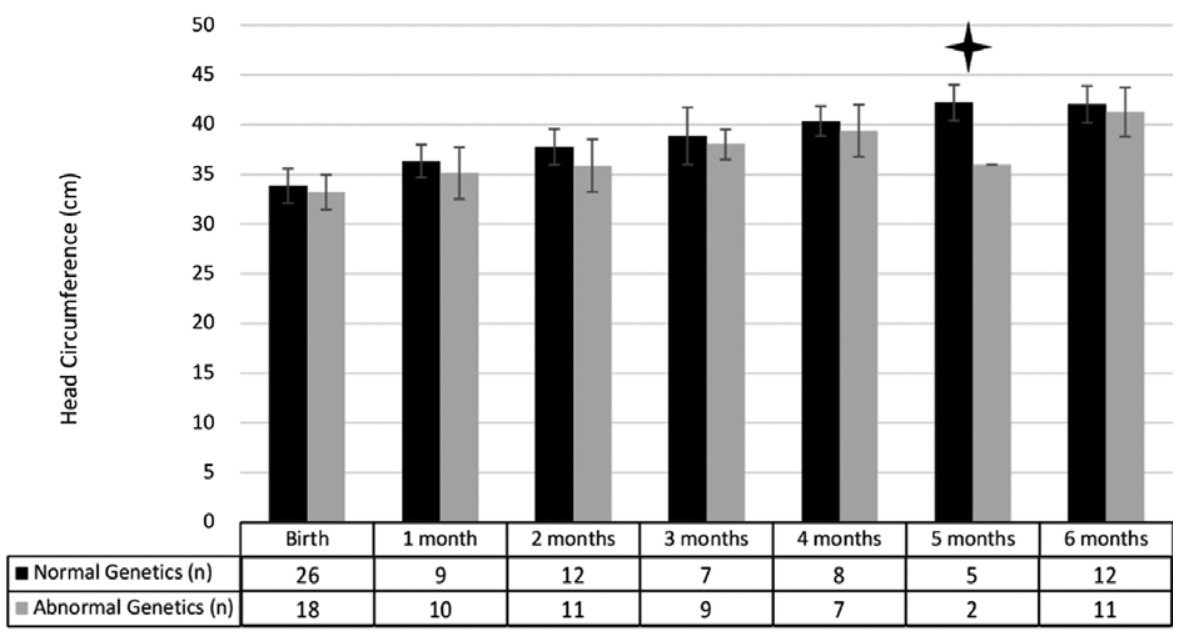

Head circumference

Figure 1. Growth parameters from birth through 6-months post-op. Black bars denote patients with normal genetics, light grey bars denote patients with abnormal genetic testing. Small lines in the bars represent standard deviation. Tables under the bars correspond to the number of patients with a measurement at that time frame for each group. P-value $<0.05$ denoted with stars above the corresponding time frame. P values for the length differences at 3 and 6 months were 0.025 and 0.003 respectively, 0.006 for the head circumference difference at 5 months. 
Table 3. Results of linear regression model evaluating the impact of single ventricle $\left(\mathrm{SV}^{\star}\right)$ versus two ventricle congenital heart disease, gender (male $\left.{ }^{\star}\right)$, gestational age, and chromosomal microarray results (normal ${ }^{\star}$ ) on weight, length, and head circumference between birth and 6 months post-operation

\begin{tabular}{|c|c|c|c|c|}
\hline & Variable & Coefficient & $95 \% \mathrm{Cl}$ & $\mathrm{p}$-value \\
\hline \multirow[t]{4}{*}{ Birth weight } & SV versus $2 \mathrm{~V}$ & -0.111 & $-0.423,0.2$ & 0.476 \\
\hline & Gender & -0.204 & $-0.548,0.139$ & 0.237 \\
\hline & GA & 0.013 & $0.011,0.015$ & $<0.001$ \\
\hline & CMA results & -0.096 & $-0.426,0.233$ & 0.559 \\
\hline \multirow[t]{4}{*}{ 1-month wt. } & SV versus $2 \mathrm{~V}$ & -0.016 & $-0.347,0.315$ & 0.922 \\
\hline & Gender & -0.415 & $-0.795,-0.036$ & 0.033 \\
\hline & $\mathrm{GA}$ & 0.014 & $0.012,0.016$ & $<0.001$ \\
\hline & CMA results & -0.129 & $-0.497,0.24$ & 0.485 \\
\hline \multirow[t]{4}{*}{ 2-month wt. } & $\mathrm{SV}$ versus $2 \mathrm{~V}$ & 0.088 & $-0.32,0.4197$ & 0.666 \\
\hline & Gender & -0.191 & $-0.641,0.258$ & 0.396 \\
\hline & GA & 0.015 & $0.013,0.018$ & $<0.001$ \\
\hline & CMA results & -0.131 & $-0.3,0.563$ & 0.544 \\
\hline \multirow[t]{4}{*}{ 3-month wt. } & SV versus $2 \mathrm{~V}$ & 0.013 & $-0.481,0.506$ & 0.959 \\
\hline & Gender & -0.22 & $-0.772,0.327$ & 0.418 \\
\hline & $\mathrm{GA}$ & 0.019 & $0.015,0.021$ & $<0.001$ \\
\hline & CMA results & 0.282 & $-0.247,0.811$ & 0.287 \\
\hline \multirow[t]{4}{*}{ 4-month wt. } & SV versus $2 \mathrm{~V}$ & 0.202 & $-0.313,0.717$ & 0.43 \\
\hline & Gender & -0.492 & $-1.106,0.122$ & 0.112 \\
\hline & GA & 0.02 & $0.017,0.024$ & $<0.001$ \\
\hline & CMA results & -0.006 & $-0.602,0.589$ & 0.983 \\
\hline \multirow[t]{4}{*}{ 5-month wt. } & SV versus $2 \mathrm{~V}$ & 0.314 & $-0.316,0.944$ & 0.315 \\
\hline & Gender & -0.462 & $-1.091,0.167$ & 0.143 \\
\hline & $\mathrm{GA}$ & 0.021 & $0.0147,0.025$ & $<0.001$ \\
\hline & CMA results & 0.076 & $-0.497,0.649$ & 0.786 \\
\hline \multirow[t]{4}{*}{ 6-month wt. } & SV versus $2 \mathrm{~V}$ & -0.001 & $-0.536,0.533$ & 0.996 \\
\hline & Gender & -0.226 & $-0.827,0.376$ & 0.453 \\
\hline & GA & 0.024 & $0.021,0.028$ & $<0.001$ \\
\hline & CMA results & 0.211 & $-0.369,0.791$ & 0.466 \\
\hline \multirow[t]{4}{*}{ Birth length } & SV versus $2 \mathrm{~V}$ & 0.255 & $-1.412,1.923$ & 0.759 \\
\hline & Gender & -0.611 & $-2.545,1.324$ & 0.527 \\
\hline & GA & 0.182 & $0.171,0.194$ & $<0.001$ \\
\hline & CMA results & 0.058 & $-1.824,1.94$ & 0.951 \\
\hline \multirow[t]{4}{*}{ 1-month lt. } & SV versus $2 \mathrm{~V}$ & -0.592 & $-2.148,0.963$ & 0.445 \\
\hline & Gender & -1.018 & $-2.862,0.826$ & 0.270 \\
\hline & GA & 0.196 & $0.186,0.206$ & $<0.001$ \\
\hline & CMA results & 0.146 & -1.573 .1 .865 & 0.864 \\
\hline \multirow[t]{4}{*}{ 2-month It. } & $\mathrm{SV}$ versus $2 \mathrm{~V}$ & 0.554 & $-1.272,2.381$ & 0.542 \\
\hline & Gender & -0.443 & $-2.434,1.548$ & 0.655 \\
\hline & GA & 0.198 & $0.186,0.209$ & $<0.001$ \\
\hline & CMA results & 1.569 & $-0.33,3.468$ & 0.103 \\
\hline \multirow[t]{4}{*}{ 3-month It. } & SV versus $2 \mathrm{~V}$ & -0.674 & $-2.837,1.4896$ & 0.531 \\
\hline & Gender & -0.177 & $-2.482,2.128$ & 0.877 \\
\hline & GA & 0.212 & $0.198,0.226$ & $<0.001$ \\
\hline & CMA results & 2.185 & $-0.041,4.411$ & 0.54 \\
\hline
\end{tabular}

Table 3. (Continued)

\begin{tabular}{|c|c|c|c|c|}
\hline & Variable & Coefficient & $95 \% \mathrm{Cl}$ & $\mathrm{p}$-value \\
\hline \multirow[t]{4}{*}{ 4-month It. } & SV versus $2 \mathrm{~V}$ & 1.148 & $-1.728,4.024$ & 0.42 \\
\hline & Gender & -0.922 & $-4.3221,2.477$ & 0.583 \\
\hline & $\mathrm{GA}$ & 0.216 & $0.197,0.234$ & $<0.001$ \\
\hline & CMA results & 1.556 & $-1.765,4.878$ & 0.345 \\
\hline \multirow[t]{4}{*}{ 5-month lt. } & SV versus $2 \mathrm{~V}$ & 0.51 & $-3.779,4.779$ & 0.806 \\
\hline & Gender & -3.17 & $-7.466,1.125$ & 0.138 \\
\hline & GA & 0.23 & $0.205,0.255$ & $<0.001$ \\
\hline & CMA results & 1.454 & $-2.221,5.128$ & 0.417 \\
\hline \multirow[t]{4}{*}{ 6-month lt. } & SV versus $2 \mathrm{~V}$ & 0.953 & $-1.086,2.991$ & 0.350 \\
\hline & Gender & -0.719 & $-3.186,1.748$ & 0.558 \\
\hline & GA & 0.223 & $0.21,0.237$ & $<0.001$ \\
\hline & CMA results & 3.904 & $1.585,6.223$ & 0.002 \\
\hline \multirow{4}{*}{$\begin{array}{l}\text { Birth head } \\
\text { circumference }\end{array}$} & SV versus $2 \mathrm{~V}$ & 0.414 & $-0.519,1.347$ & 0.375 \\
\hline & Gender & -0.489 & $-1.551,0.573$ & 0.358 \\
\hline & GA & 0.121 & $0.115,0.127$ & $<0.001$ \\
\hline & CMA results & 0.727 & $-0.281,1.734$ & 0.153 \\
\hline \multirow[t]{4}{*}{ 1-month HC } & SV versus $2 \mathrm{~V}$ & 1.987 & $-2.223,6.196$ & 0.332 \\
\hline & Gender & -0.176 & $-4.693,4.341$ & 0.935 \\
\hline & GA & 0.12 & $0.094,0.146$ & $<0.001$ \\
\hline & CMA results & 0.189 & $-4.416,4.525$ & 0.927 \\
\hline \multirow[t]{4}{*}{ 2-month HC } & SV versus $2 \mathrm{~V}$ & 0.301 & $-1.566,2.167$ & 0.740 \\
\hline & Gender & -1.183 & $-3.507,1.141$ & 0.300 \\
\hline & GA & 0.134 & $0.12,0.148$ & $<0.001$ \\
\hline & CMA results & 1.134 & $-1.189,3.457$ & 0.320 \\
\hline \multirow[t]{4}{*}{ 3-month HC } & SV versus $2 \mathrm{~V}$ & 1.776 & $-0.598,4.149$ & 0.129 \\
\hline & Gender & -1.558 & $-3.793,0.678$ & 0.155 \\
\hline & GA & 0.13 & $0.115,0.146$ & $<0.001$ \\
\hline & CMA results & 1.589 & $-0.704,3.882$ & 0.157 \\
\hline \multirow[t]{4}{*}{ 4-month HC } & SV versus $2 \mathrm{~V}$ & 0.654 & $-2.426,3.734$ & 0.649 \\
\hline & Gender & -1.22 & $-4.517,2.077$ & 0.433 \\
\hline & $\mathrm{GA}$ & 0.145 & $0.129,2.077$ & $<0.001$ \\
\hline & CMA results & 0.413 & $-2.374,3.201$ & 0.750 \\
\hline \multirow[t]{4}{*}{ 5-month HC } & SV versus $2 \mathrm{~V}$ & -0.279 & $-6.997,6.439$ & 0.903 \\
\hline & Gender & 0.508 & $-7.297,8.313$ & 0.849 \\
\hline & GA & 0.158 & $0.094,0.174$ & 0.002 \\
\hline & CMA results & 6.524 & $-0.052,13.101$ & 0.051 \\
\hline \multirow[t]{4}{*}{ 6-month HC } & SV versus $2 \mathrm{~V}$ & -0.084 & $-1.73,1.562$ & 0.916 \\
\hline & Gender & -1.04 & $-2.978,0.899$ & 0.276 \\
\hline & GA & 0.154 & $0.144,0.164$ & $<0.001$ \\
\hline & CMA results & 0.848 & $-0.981,2.678$ & 0.344 \\
\hline
\end{tabular}

Abbreviations: $\mathrm{SV}=$ single ventricle; $2 \mathrm{~V}=$ two ventricle; $\mathrm{CHD}=$ congenital heart disease; $\mathrm{GA}=$ gestational age; $\mathrm{CMA}=$ chromosomal microarray; $\mathrm{HC}=$ head circumference; $\mathrm{mo}=$ months; $\mathrm{wt}=$ weight; It $=$ length .

p-value $<0.05$ in bold.

*indicated reference category for regression model. 
Table 4. Comparison of the feeding methods seen in infants with normal and abnormal genetic testing from the post-operative period to 5 months postoperation

\begin{tabular}{|c|c|c|c|c|c|}
\hline & Post Operation & 2 Months & 3 Months & 4 Months & 5 Months \\
\hline & \multicolumn{5}{|c|}{ Feeding route } \\
\hline & \multicolumn{5}{|c|}{ Normal genetic testing $\mathbf{n}(\%)$} \\
\hline Enteral tube & $30(96)$ & $6(19)$ & $5(17)$ & $5(17)$ & $3(10)$ \\
\hline Oral & $1(4)$ & $16(52)$ & $21(70)$ & $22(76)$ & $22(80)$ \\
\hline \multirow[t]{2}{*}{ Combo } & $0(0)$ & $9(29)$ & $4(13)$ & $2(7)$ & $3(10)$ \\
\hline & \multicolumn{5}{|c|}{ Abnormal genetic testing $\mathbf{n}(\%)$} \\
\hline Enteral tube & $20(95)$ & $2(10)$ & $2(10)$ & $2(12.5)$ & $2(13)$ \\
\hline Oral & $1(5)$ & $7(37)$ & $9(45)$ & $9(56.25)$ & $9(60)$ \\
\hline Combo & $0(0)$ & $10(53)$ & $9(45)$ & $5(31.25)$ & $4(27)$ \\
\hline$z$ & $z=0.283$ & $x^{2}=3.513$ & $X^{2}=6.259$ & $x^{2}=6.016$ & $x^{2}=3.11$ \\
\hline p & 0.777 & 0.173 & 0.04 & 0.04 & 0.211 \\
\hline
\end{tabular}

non-cardiac abnormalities in patients with genetic abnormalities. ${ }^{16}$ All patients in the study, regardless of genetic testing result, received an increasing amount of feeds orally during the study, in line with previous studies. ${ }^{8}$ Overall, it is our opinion that the number of infants in both groups who require enteral tubes to meet nutrition and growth goals is too high. It is our hope to decrease the need for enteral tube feeds in the future through standardisation of preoperative feedings, promoting early post-operative feeds, and early, ongoing involvement of therapists with expertise in infant feeding.

This study has several important limitations. First, the small sample size makes detection of small but significant impacts of the various clinical variables on growth and feeding impossible. Second, clinical practice variation between providers and over the study time period also limits the strength of study findings. As an example, feeding neonates prior to cardiac surgery was almost unheard of 10 years ago. Pre-operative oral feeding is now standard at our institution in infants deemed stable. Third, almost half of eligible patients during our study time frame were excluded due to various reasons, including death prior to the end of the study time frame ( 6 months post-operative). Fourth, there are patients with missing data especially length or head circumference, which are typically not measured at each cardiology clinic visit and would only be included in our electronic medical record if their pediatrician was in our medical system. Finally, other variables not evaluated such as feeding therapy, vocal cord dysfunction, or length of intubation may have important impacts on growth and ability to feed orally. ${ }^{12,26}$

Our retrospective chart review of growth and feeding methods of infants following neonatal surgery for critical CHD emphasises some of the important factors that still need to be optimised in these children. Continued work on early oral feedings and ensuring optimal caloric intake for each infant is needed, regardless of genetics. Those with genetic abnormalities are more likely to have multifactorial difficulties with growth and oral feeding than their counterparts with normal genetics. It has been shown that a strong emphasis on growth and nutrition regardless of genetic testing can help mitigate growth differences. Our findings show that our centre has adequate protocols in place to alleviate any growth differences between those with and without genetic abnormalities, but children with genetic abnormalities have more difficulty achieving oral feedings and require longer tube feeds to maintain
Table 5. Results of multinomial logistic regression model evaluating the association between method of feeding (enteral tube feed as base outcome) and single ventricle $\left(\mathrm{SV}^{\star}\right)$ versus two ventricle congenital heart disease, gender $\left(\right.$ male $\left.^{\star}\right)$, gestational age, and chromosomal microarray results $\left(\right.$ normal $\left.{ }^{\star}\right)$ between the post-operative period and 5 months post-operation

\begin{tabular}{|c|c|c|c|}
\hline & Variable & Odd ratio $(95 \% \mathrm{Cl})$ & $\mathrm{p}$-value \\
\hline \multirow[t]{4}{*}{ Post-Operation } & SV versus $2 \mathrm{~V}$ & $4.079(0.023,736.58$ & 0.596 \\
\hline & Gender & $30.766(0.02,48,042)$ & 0.361 \\
\hline & GA & $0.968(0.928,1.01)$ & 0.138 \\
\hline & CMA results & $1.627,(0.092,29.9)$ & 0.740 \\
\hline \multicolumn{4}{|c|}{ RRR $(95 \% \mathrm{CI})$} \\
\hline \multirow[t]{4}{*}{ 1-month } & SV versus $2 \mathrm{~V}$ & $1.198(0.219,6.552)$ & 0.835 \\
\hline & Gender & $1.717(0.225,13.12)$ & 0.602 \\
\hline & GA & $0.997(0.985,1.01)$ & 0.602 \\
\hline & CMA results & $2.124(0.263,17.134)$ & 0.480 \\
\hline \multirow[t]{4}{*}{ 2-month } & SV versus $2 \mathrm{~V}$ & $-0.768(0.128,4.616)$ & 0.773 \\
\hline & Gender & $2.876(0.338,24.434)$ & 0.333 \\
\hline & GA & $1.005(0.994,1.017)$ & 0.389 \\
\hline & CMA results & $0.441(0.06,3.261)$ & 0.422 \\
\hline \multirow[t]{4}{*}{ 3-month } & SV versus $2 \mathrm{~V}$ & $1.655(0.197,13.92)$ & 0.643 \\
\hline & Gender & $1.297(0.133,12.608)$ & 0.823 \\
\hline & GA & $1.002(0.989,1.015)$ & 0.738 \\
\hline & CMA results & $0.22(0.024,2.016)$ & 0.180 \\
\hline \multirow[t]{4}{*}{ 4-month } & SV versus $2 \mathrm{~V}$ & $3.051(0.472,19.714)$ & 0.241 \\
\hline & Gender & $0.327(0.04,2.65)$ & 0.295 \\
\hline & GA & $0.999(0.986,1.012)$ & 0.866 \\
\hline & CMA results & $1.102(0.118,10.269)$ & 0.932 \\
\hline \multirow[t]{4}{*}{ 5-month } & SV versus $2 \mathrm{~V}$ & $1.123(0.113,11.127)$ & 0.921 \\
\hline & Gender & $1.821(0.167,19.909)$ & 0.623 \\
\hline & GA & $1.968 \mathrm{E}-4(0.986,1.016)$ & 0.897 \\
\hline & CMA results & $1.958(0.218,17.584)$ & 0.549 \\
\hline
\end{tabular}

Abbreviations: $\mathrm{RRR}=$ relative risk ratio; $\mathrm{Cl}=$ confidence intervals; $\mathrm{SV}=$ single ventricle; $2 \mathrm{~V}=$ two ventricle; $\mathrm{CHD}=$ congenital heart disease; $\mathrm{GA}=$ gestational age; $\mathrm{CMA}=$ chromosomal microarray; $\mathrm{HC}=$ head circumference; $\mathrm{mo}=$ months; $\mathrm{wt}=$ weight; $\mathrm{It}=$ length.

p-value $<0.05$ in bold.

*indicated reference category for regression model.

growth. Multicentre studies concentrating on specific cardiac abnormalities with larger numbers of infants are required to further elucidate differences.

Acknowledgements. None.

Financial Support. This research received no specific grant from any funding agency, commercial or not-for-profit sectors.

\section{Conflicts of Interest. None.}

Ethical Standards. The authors assert that all procedures contributing to this work comply with the ethical standards of the relevant national guidelines on human experimentation and with the Helsinki Declaration of 1975, as revised in 2008, and has been approved by the institutional committees (Institutional Review Board at the University of Iowa). 


\section{References}

1. Hoffman JI, Kaplan S. The incidence of congenital heart disease. J Am Coll Cardiol 2002; 39: 1890-1900.

2. Shrivastava S. Timing of surgery/catheter intervention in common congenital cardiac defects. Indian J Pediatr 2000; 67: 273-277.

3. Martin GR, Jonas RA. Surgery for Congenital Heart Disease: Improvements in Outcomes. Am J Perinatol 2018; 35: 557-560.

4. Hehir DA, Cooper DS, Walters EM, Ghanayem NS. Feeding, growth, nutrition, and optimal interstage surveillance for infants with hypoplastic left heart syndrome. Cardiol Young 2011; 21 (Suppl 2): 59-64.

5. Medoff-Cooper B, Irving SY, Hanlon AL, et al. The Association among Feeding Mode, Growth, and Developmental Outcomes in Infants with Complex Congenital Heart Disease at 6 and 12 Months of Age. J Pediatr 2016; 169: 154-159.e151.

6. Slicker J, Sables-Baus S, Lambert LM, Peterson LE, Woodard FK, Ocampo EC. Perioperative Feeding Approaches in Single Ventricle Infants: A Survey of 46 Centers. Congenit Heart Dis 2016; 11: 707-715.

7. Spillane NT, Kashyap S, Bateman D, Weindler M, Krishnamurthy G. Comparison of Feeding Strategies for Infants With Hypoplastic Left Heart Syndrome: A Randomized Controlled Trial. World J Pediatr Congenit Heart Surg 2016; 7: 446-453.

8. Anderson JB, Beekman RH, 3rd, Border WL, et al. Lower weight-for-age z score adversely affects hospital length of stay after the bidirectional Glenn procedure in 100 infants with a single ventricle. J Thorac Cardiovasc Surg 2009; 138: 397-404.e391.

9. Anderson JB, Iyer SB, Schidlow DN, et al. Variation in growth of infants with a single ventricle. J Pediatr 2012; 161: 16-21.e11; quiz 21.e12-13.

10. Tabbutt S, Ghanayem N, Ravishankar C, et al. Risk factors for hospital morbidity and mortality after the Norwood procedure: A report from the Pediatric Heart Network Single Ventricle Reconstruction trial. J Thorac Cardiovasc Surg 2012; 144: 882-895.

11. Hansson L, Ohlund I, Lind T, Stecksen-Blicks C, Rydberg A. Dietary intake in infants with complex congenital heart disease: a case-control study on macro- and micronutrient intake, meal frequency and growth. J Hum Nutr Diet 2016; 29: 67-74.

12. Skinner ML, Halstead LA, Rubinstein CS, Atz AM, Andrews D, Bradley SM. Laryngopharyngeal dysfunction after the Norwood procedure. J Thorac Cardiovasc Surg 2005; 130: 1293-1301.

13. Patel A, Hickey E, Mavroudis C, et al. Impact of noncardiac congenital and genetic abnormalities on outcomes in hypoplastic left heart syndrome. Ann Thorac Surg 2010; 89: 1805-1813; discussion 1813-1804.
14. Rosenbloom ST, McGregor TL, Chen Q, An AQ, Hsu S, Dupont WD. Specialized Pediatric Growth Charts For Electronic Health Record Systems: the example of Down syndrome. AMIA Annu Symp Proc 2010; 2010: 687-691.

15. Alsoufi B, Gillespie S, Mahle WT, et al. The Effect of Noncardiac and Genetic Abnormalities on Outcomes Following Neonatal Congenital Heart Surgery. Semin Thorac Cardiovasc Surg 2016; 28: 105-114.

16. Simmons MA, Brueckner M. The genetics of congenital heart disease... understanding and improving long-term outcomes in congenital heart disease: a review for the general cardiologist and primary care physician. Curr Opin Pediatr 2017; 29: 520-528.

17. Moons P, Sluysmans T, De Wolf D, et al. Congenital heart disease in 111 225 births in Belgium: birth prevalence, treatment and survival in the 21st century. Acta Paediatr 2009; 98: 472-477.

18. Samanek M. Boy:girl ratio in children born with different forms of cardiac malformation: a population-based study. Pediatr Cardiol 1994; 15: 53-57.

19. Diogenes TCP, Mourato FA, de Lima Filho JL, Mattos SDS. Gender differences in the prevalence of congenital heart disease in Down's syndrome: a brief meta-analysis. BMC Med Genet 2017; 18: 111.

20. Evans CF, Sorkin JD, Abraham DS, Wehman B, Kaushal S, Rosenthal GL. Interstage Weight Gain Is Associated With Survival After First-Stage Single-Ventricle Palliation. Ann Thorac Surg 2017; 104: 674-680.

21. Burch PT, Gerstenberger E, Ravishankar C, et al. Longitudinal assessment of growth in hypoplastic left heart syndrome: results from the single ventricle reconstruction trial. J Am Heart Assoc 2014; 3: e000079.

22. Hurst DM, Oster ME, Smith S, Clabby ML. Is Clinic Visit Frequency Associated with Weight Gain During the Interstage Period? A Report from the Joint Council on Congenital Heart Disease National Pediatric Cardiology Quality Improvement Collaborative (JCCHD-NPCQIC). Pediatr Cardiol 2015; 36: 1382-1385.

23. Slicker J, Hehir DA, Horsley M, et al. Nutrition algorithms for infants with hypoplastic left heart syndrome; birth through the first interstage period. Congenit Heart Dis 2013; 8: 89-102.

24. Sano S, Huang SC, Kasahara S, Yoshizumi K, Kotani Y, Ishino K. Risk factors for mortality after the Norwood procedure using right ventricle to pulmonary artery shunt. Ann Thorac Surg 2009; 87: 178-185; discussion 185-176.

25. Burch PT, Ravishankar C, Newburger JW, et al. Assessment of Growth 6 Years after the Norwood Procedure. J Pediatr 2017; 180: 270-274.e276.

26. Indramohan G, Pedigo TP, Rostoker N, Cambare M, Grogan T, Federman MD. Identification of Risk Factors for Poor Feeding in Infants with Congenital Heart Disease and a Novel Approach to Improve Oral Feeding. J Pediatr Nurs 2017; 35: 149-154. 